\title{
Pulmonary light chain deposition disease: a case series and literature review
}

\author{
Ping Wei", Rujia Tao", Yihan Liu, Huikang Xie, Sen Jiang, Dong Yu, Haiwen Lu, Weijun Cao \\ Department of Pulmonary and Critical Care Medicine, Shanghai Pulmonary Hospital, Tongji University, Shanghai 200082, China \\ Contributions: (I) Conception and design: W Cao, H Lu; (II) Administrative support: W Cao, H Lu; (III) Provision of study materials or patients: W \\ Cao, H Lu; (IV) Collection and assembly of data: P Wei, R Tao, H Xie, S Jiang, D Yu, Y Liu; (V) Data analysis and interpretation: P Wei, R Tao; (VI) \\ Manuscript writing: All authors; (VII) Final approval of manuscript: All authors. \\ \#These authors contributed equally to this study. \\ Correspondence to: Weijun Cao, MD, PhD; Haiwen Lu, MD. Department of Pulmonary and Critical Care Medicine, Shanghai Pulmonary Hospital, \\ Tongji University, Shanghai 200082, China. Email: weijuncao@126.com; haiwen_lu@163.com.
}

Background: Light chain deposition disease (LCDD) is a systemic disorder typically characterized by nonamyloid monoclonal immunoglobulin light chain deposition in tissues. LCDD is recognized as a multisystem disease, in which the kidneys and liver are often affected. However, it is rarely encountered as a localized pulmonary disease. This study set out to characterize the clinical manifestations and features of pulmonary light-chain deposition disease (PLCDD) by conducting a retrospective analysis of clinical data obtained from patients, with the aim of improving clinical understanding of PLCDD.

Methods: Data from inpatients diagnosed with PLCDD at Shanghai Pulmonary Hospital (Shanghai, China) between January 2010 and December 2018 were retrospectively collected and analyzed.

Results: A total of 4 PLCDD patients confirmed with PLCDD by pulmonary tissue biopsy were analyzed. All of the patients were female and were found by physical examination. Chest images of each patient's lungs showed multiple cystic cavities with nodules. A history of Sjogren's syndrome was present with 1 patient, 2 patients were diagnosed with Sjogren's syndrome after surgery (including 1 diagnosed with Sjogren's syndrome in the 8th year of follow up), and 3 patients had leukopenia. The longest follow-up period was 8 years. During the follow-up period, 2 patients developed pulmonary lesions (1 patient had an enlarged original cystic lesion in basal segment of right lower lobe 2 years after surgery, while the other developed new nodules 7 years after surgery).

Conclusions: PLCDD is characterized by multiple cystic changes with nodules in both lungs and can be easily complicated by lymphoid diseases such as Sjogren's syndrome. The clinical symptoms cannot be characterized, and the diagnosis depends on lung biopsy.

Keywords: Pulmonary light-chain deposition disease (PLCDD); chest computed tomography (chest CT); prognosis

Submitted Feb 20, 2020. Accepted for publication Apr 22, 2020.

doi: 10.21037/atm-20-2708

View this article at: http://dx.doi.org/10.21037/atm-20-2708

\section{Introduction}

First described by Randall in 1976 (1), light chain protein deposition disease (LCDD) is a multisystem disease caused by excessive production of monoclonal immunoglobulin light chain and tissue deposition affecting the kidneys, liver, and heart. The kidney is the most commonly affected organ and approximately $20 \%$ of patients have renal failure requiring dialysis $(2,3)$. Apart from the above mentioned organs, pulmonary involvement is relatively rare (4-8). In 1987, light chain deposition of non-amyloid nodules was limited to the lung and was considered as a new clinicopathological entity of LCDD (9). Patients are usually 
asymptomatic, but some have cough and dyspnea. In 2006, Colombat et al. (10) reported three cases of LCDD only involving the lungs, presenting as a bilateral cystic lung disorder with severe chronic respiratory failure leading to lung transplantation. Owing to its relatively low incidence and difficulties in diagnosis, limited data are available on PLCDD.

This study reviewed the clinical data of patients confirmed with pulmonary light-chain deposition disease (PLCDD) by lung biopsy at Shanghai Pulmonary Hospital Affiliated to Tongji University between January 2011 and December 2018, and summarized their clinical manifestations, laboratory examination results, diagnosis, treatment, and outcomes. The relevant literature was also reviewed.

\section{Methods}

Data were retrospectively collected from inpatients diagnosed with PLCDD at the Shanghai Pulmonary Hospital between January 2010 and December 2018. The diagnosis of PLCDD was based on the standardized criteria: hematoxylin eosin $(\mathrm{H} \& \mathrm{E})$ staining of the patients' lung tissue showed that there was no deposition of structural substances in the red staining, while the Congo red staining was negative, and the light chain immunohistochemistry staining was positive. The pathological examination results were independently confirmed by at least two pathologists.

The patients' medical records were obtained and the following variables were collected: general and anthropometric information; clinical symptoms; imaging evaluation; serological and urological indicators; and pulmonary function parameters. The chest radiographs or computed tomography (CT) images were read independently by two investigators, and were finally analyzed and summarized after reviewed by a deputy director. The distribution, size, shape, margin, and adjacent tissues of the cystic lesions and nodules were observed and analyzed through the pulmonary and mediastinal windows, and changes in the bronchial wall and mediastinal lymph nodes of the pulmonary hilum were also observed. All of the patients were followed up after discharge, and the longest follow-up period lasted 8 years.

It is well known that the prognosis of LCDD depends on the number and nature of the affected organs. Adequate treatment for PLCDD has not been established. At present, inhibition of the production of light chains should be the goal of treatment to avoid further deposition in the unaffected organs. Furthermore, medical management of organ dysfunction should be provided. Corticosteroids and cytotoxic drugs have different results in the treatment of lung LCDD. Lung transplantation has also been reported in the treatment of PLCDD, but the long-term expectation is worth further study. In general, potential hematologic diseases and superimposed multiple organ LCDD lead to poor prognosis.

The study was approved by the Ethics Committee of Shanghai Pulmonary Hospital. All aspects of the study were performed in accordance with the relevant guidelines and regulations.

\section{Results}

\section{General characteristics}

A total of 4 biopsy-confirmed PLCDD patients were included in this study, all of whom were female and aged from 36-64 years old. All of the patients were identified by physical examination and none of them demonstrated obvious respiratory symptoms. One patient had suffered from Sjogren's syndrome for 5 years, while the other 3 had no notable medical history. Before the operation, 3 patients were presumptively diagnosed with lung cancer based on the solitary pulmonary nodule, and 1 patient was diagnosed with lymphangiomyomatosis (LAM). In 1 case, lung nodule biopsy during the operation indicated the presence of adenocarcinoma in situ (AIS) (right middle lung) (Table 1). Leucopenia occurred in 3 of the 4 patients. Two patients tested positive for antinuclear antibody, antiSSA antibody, and anti-SSB antibody. Only 2 of the patients were examined for urinary M-protein after surgery, and both were negative. None of the patients experienced liver, kidney, heart, or nervous system involvement (Table 1).

\section{Pulmonary function}

Arterial blood gas analysis and pulmonary ventilation were performed in all 4 patients (Table 2). All of the patients had normal arterial blood gas, 2 cases had mild obstructive ventilatory dysfunction, and 2 had mild restrictive ventilatory dysfunction. Small airway dysfunction was detected in all of the patients (with decreased MEF25).

\section{CT imaging}

All cases were scanned by chest CT. The scanning tube 
Table 1 Clinical findings in 4 patients with pulmonary light chain deposition disease

\begin{tabular}{|c|c|c|c|c|c|c|c|c|c|c|c|}
\hline $\begin{array}{l}\text { Case } \\
\text { No. }\end{array}$ & Age & Sex & $\begin{array}{l}\text { Suspected } \\
\text { diagnosis }\end{array}$ & $\begin{array}{c}\text { WBC } \\
\left(\times 10^{9} / \mathrm{L}\right)\end{array}$ & $\begin{array}{c}\mathrm{M} \\
\text { protein }\end{array}$ & Presentation & $\begin{array}{c}\text { Hematological } \\
\text { disease }\end{array}$ & Comorbidities & Biopsy & $\begin{array}{c}\text { Follow-up } \\
\text { (months) }\end{array}$ & Outcomes \\
\hline 1 & 64 & $\mathrm{~F}$ & Lung cancer & 3.9 & NA & $\begin{array}{l}\text { Incidental, } \\
\text { SS for } 5 \\
\text { years }\end{array}$ & NED & No & $\begin{array}{l}\text { Right-middle } \\
\text { lobe, anterior basal } \\
\text { segment of right } \\
\text { lower lobe }\end{array}$ & 41 & Stable \\
\hline 3 & 61 & $\mathrm{~F}$ & $\begin{array}{l}\text { Lung cancer, } \\
\text { pneumatocele }\end{array}$ & 2.8 & $(-)$ & $\begin{array}{l}\text { Incidental, } \\
\text { SS for } 1 \\
\text { month after } \\
\text { surgery }\end{array}$ & NED & No & $\begin{array}{l}\text { Right-middle lobe, } \\
\text { Basal segment of } \\
\text { right lower lobe }\end{array}$ & 13 & $\begin{array}{l}\text { An enlarged } \\
\text { original cystic } \\
\text { lesion and } \\
\text { underwent } \\
\text { operation biopsy }\end{array}$ \\
\hline
\end{tabular}

SS, Sjogren's syndrome; N/A, not available; NED, no evidence of disease at the number of months specified in parentheses.

Table 2 Pulmonary function of 4 patients with pulmonary light chain protein deposition disease

\begin{tabular}{|c|c|c|c|c|c|c|c|}
\hline Case No. & Ventilatory disorders & FVC & FVC (\%) & FEV1 & FEV1 (\%) & FEV1/FVC (\%) & MEF25 (\%) \\
\hline 2 & Mild obstructive ventilation dysfunction & 3.53 & 117.1 & 2.21 & 88.9 & 62.6 & 35.8 \\
\hline 3 & Mild restrictive ventilation dysfunction & 1.91 & 65.6 & 1.51 & 64.3 & 78.85 & 50.7 \\
\hline 4 & Mild restrictive ventilation dysfunction & 2.41 & 75.5 & 1.9 & 72.4 & 79.04 & 29.0 \\
\hline
\end{tabular}

had a voltage of $120 \mathrm{kV}$ and a current of $115-220 \mathrm{Ma}$. The width of the collimation was $1 \mathrm{~mm}$, the thickness of the scanning layer was $1 \mathrm{~mm}$, and the pitch was $0.9 \mathrm{~mm}$. The scanning range was $1 \mathrm{~cm}$ from the glottis to the diaphragm. Multiple capsule cavities with pulmonary nodules were found in all 4 patients (Figure 1A). The cystic lesions and nodules varied in size and their distribution was not regular. Blood vessels were found in the wall of the capsule and in the cystic lesions in 4 and 3 cases, respectively (Figure $1 B, C)$. Thoracic CT showed circumscribed nodular bilateral densities, ranging in size from 8 to $15 \mathrm{~mm}$, with some exhibiting halo signs, burrs, and lobulation. Calcified nodules were detected in 3 of the patients (Figure 1D,E), and 1 of the patients showed signs of air bronchus charging. Ground glass shadow was observed in the bilateral inferior lung of 1 patient. One patient exhibited mediastinal lymphadenopathy with calcification. No pleural thickening or effusion was found in any of the patients (Table 3). During the follow-up period, two patients' CT images progressed, showing a new pulmonary nodule and enlargement of primary cystic lesions respectively (Figure 1F,G).

\section{Histology and immunohistochemistry}

All of the patients were diagnosed by open lung biopsy. Lung nodule biopsies were performed on all of the patients and cystic lesions biopsies were performed on 2 patients. One patient had AIS. Generally, biopsies from the patients contained tan-white nodules with clear boundaries ranging in diameter from $0.8-1.4 \mathrm{~cm}$. Histological examination of the H\&E sections from the biopsy showed nodular aggregates of dense eosinophils with lymphoplasmacytic and giant cell reaction (Figure 2A). The sections stained with Congo red showed a deep orange-red; however, 

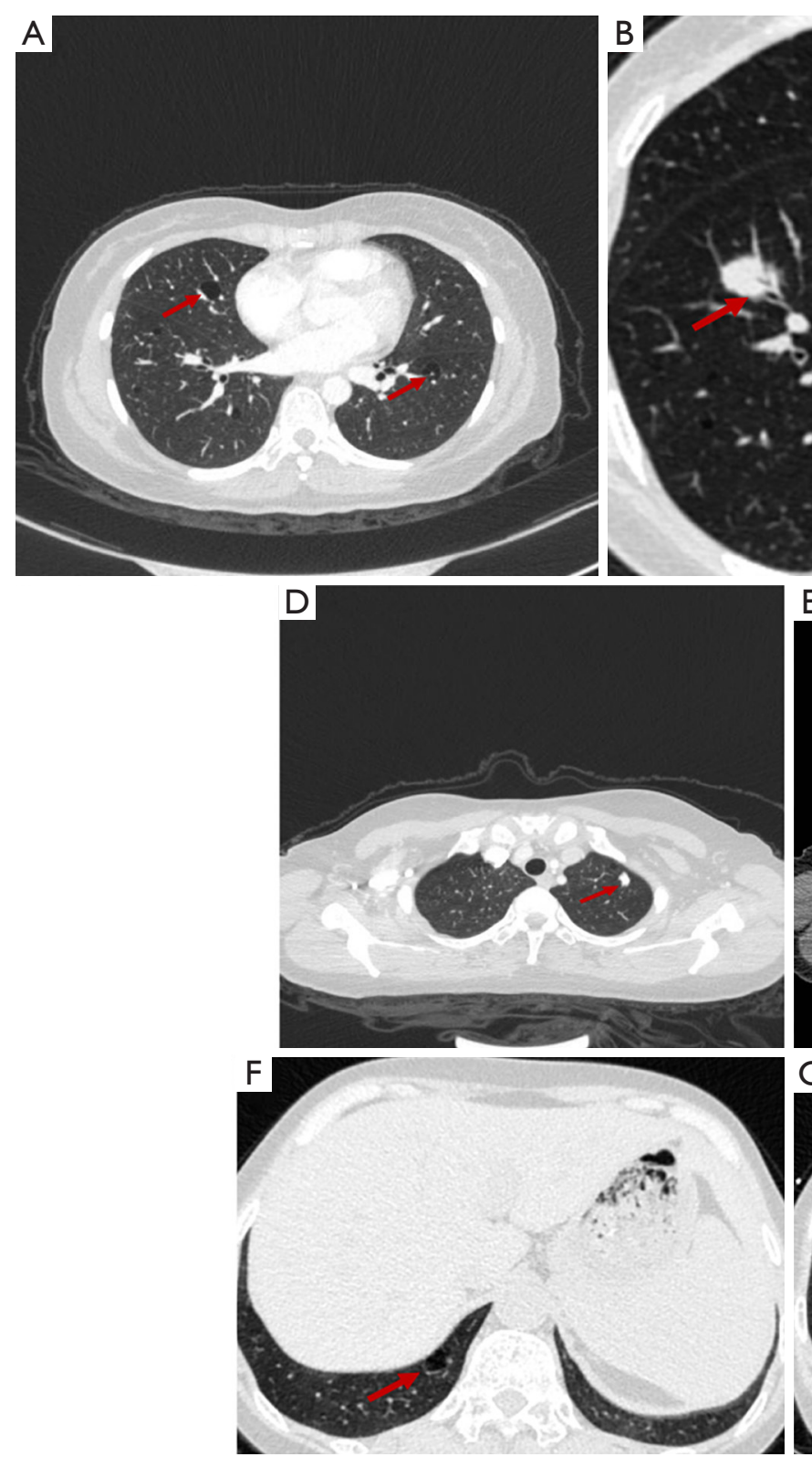
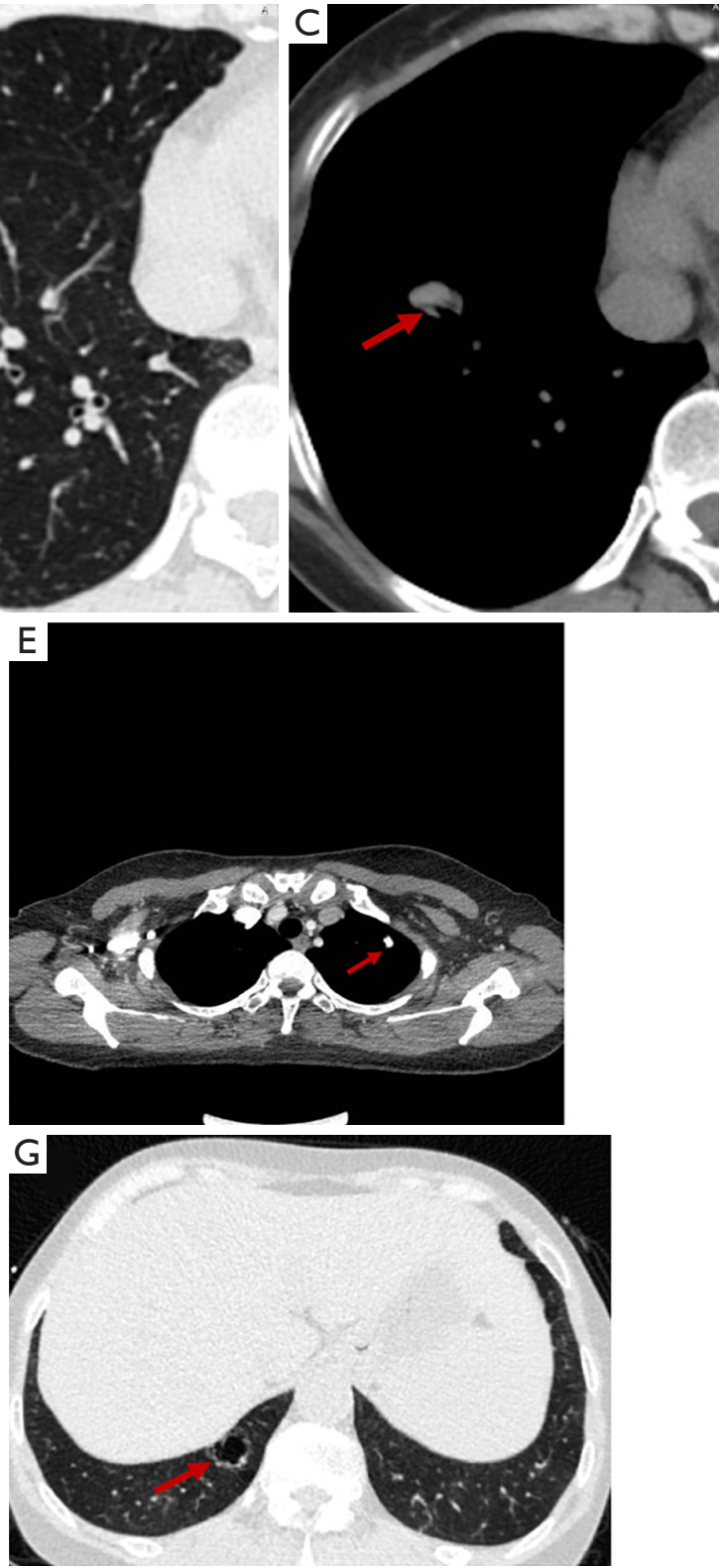

Figure 1 High-resolution computed tomography (CT) scan. (A) Multiple capsule cavity with pulmonary nodules were demonstrate in CT scans (arrows); (B,C) blood vessels were found in the wall of the capsule; $(\mathrm{D}, \mathrm{E})$ there are some micronodules present with calcification; (F,G) two years after operation, an enlarged original cystic lesion in basal segment of right lower lobe.

the characteristic apple-green birefringence was lacking polarization in all cases (Figure 2B). Immunohistochemistry demonstrated positive $\kappa$ but not $\lambda$ light chain within the eosinophilic material (Figure 2C,D,E,F).

\section{Management and follow-up}

None of the patients received special treatment after surgery. One of the patients who had a history of Sjogren's syndrome before the operation had long-term use of prednisone and hydroxychloroquine. Each patient was followed up: the longest follow-up time was 103 months, with an average of 43.5 months, and the date of last follow-up was July 19, 2019. Two cases were diagnosed as Sjogren's syndrome 1 month and 8 years after operation, respectively. Consequently, these patients were treated 


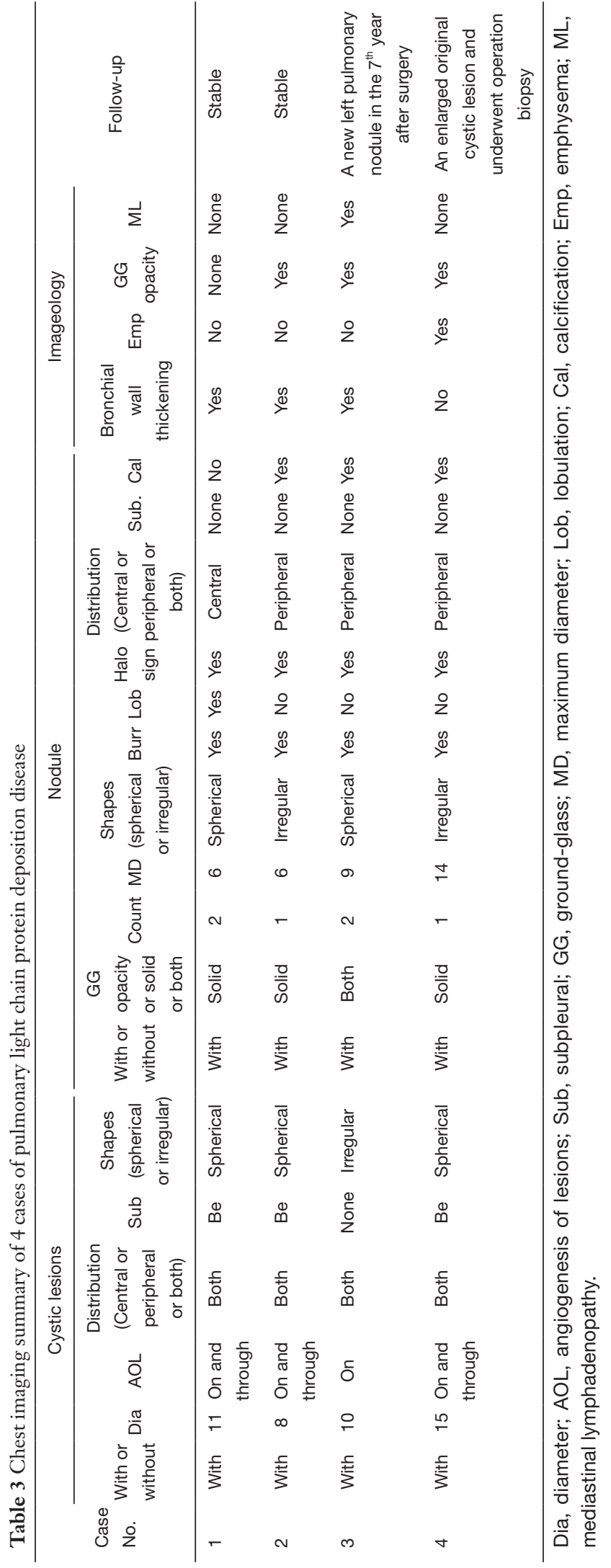

with prednisone and hydroxychloroquine and followed up by the rheumatology department. In the follow-up period, chest imaging revealed progress in 2 patients. A new left pulmonary nodule was revealed in 1 patient in the 7 th year after surgery, and another had an enlarged original cystic lesion and underwent operation biopsy (Figure 1F,G).

\section{Discussion}

LCDD is a monoclonal immunoglobulin deposition disease, which frequently involves the kidneys and liver, but rarely affects the lungs. LCDD is often secondary to lymphoproliferative disease. Only 50 cases of PLCDD, which was first identified by Kijner et al. (11) in 1988, have been reported so far. Because of the lack of familiarity clinicians and pathologists have with this kind of disease, clinical misdiagnosis and missed diagnosis are common.

In clinical practice, LCDD can develop in both men and women. Although it has been reported that the disease affects more men than women (12), clinical data on PLCDD is lacking, and in the few recent literature reports, women appear to be more commonly affected (13). All 4 of the cases in this study were female and asymptomatic. The clinical symptoms reported in previous studies were dyspnea, hemoptysis, and chest discomfort, which were related to the severity of lung involvement. Despite the 4 patients in this study experiencing no obvious clinical symptoms, they exhibited a slight decline in ventilation function with small airway dysfunction. This may be related to the deposition of light chain protein in the lung influencing matrix metalloproteinase to decompose elastic fibers, thus affecting the small airway and leading to its obstruction (14).

Few studies have focused on PLCDD imaging, but certain characteristics have been reported. Most of the patients involved in previous research had multiple cystic bilateral lesions in the lungs, but in recent years, multiple nodules have also been reported as a characteristic manifestation of PLCDD (13). Some studies have reported that pulmonary nodules may be accompanied by calcification (15). At present, multiple cystic changes and multiple pulmonary nodules are the common imaging manifestations of PLCDD; their coexistence means PLCDD should certainly be considered. On chest CT, we also found that blood vessels in the cystic wall and blood vessels passing through the cystic lesions, therefore, it is also necessary to consider the possibility of PLCDD when these observations are made. Previous literature has reported that 

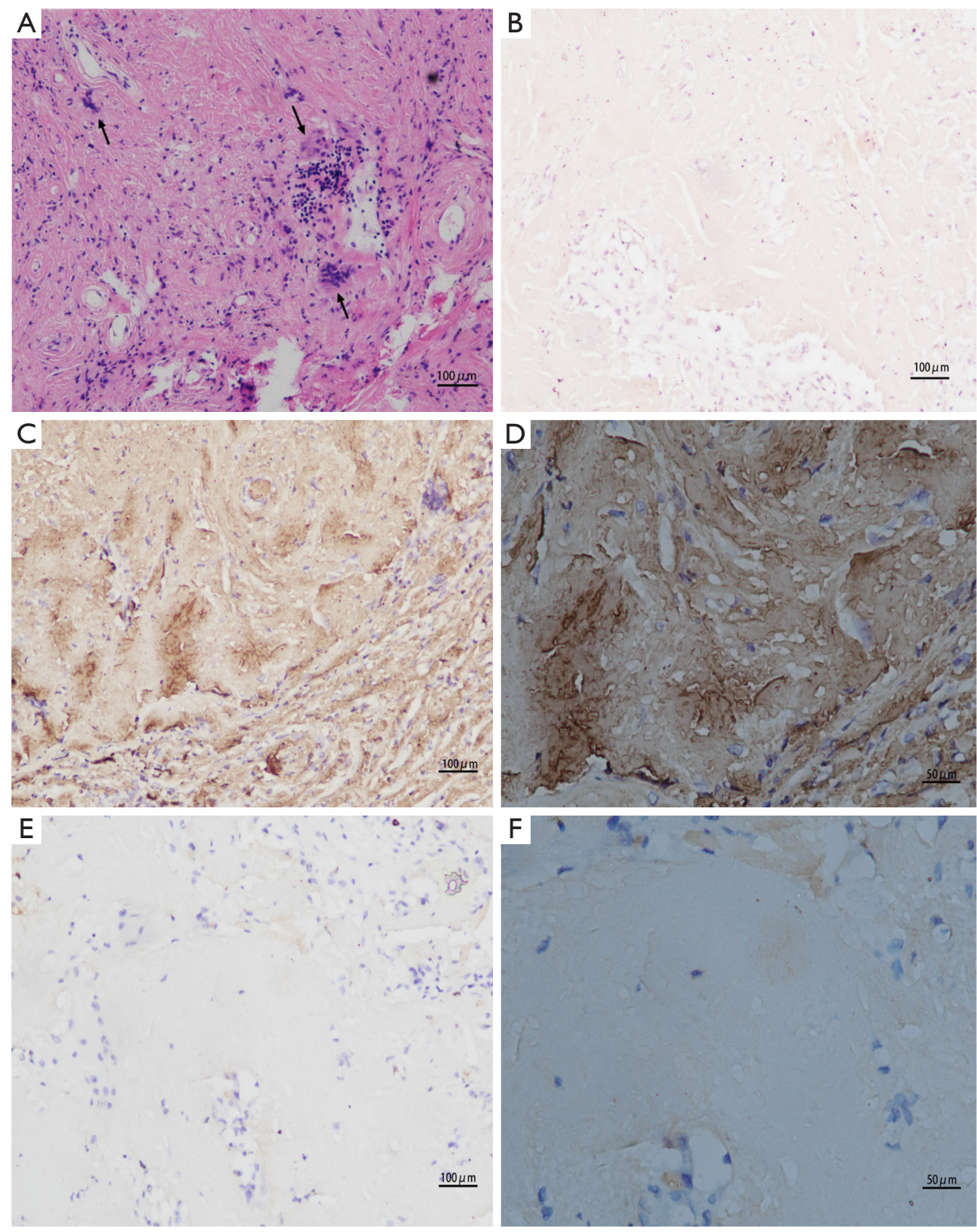

Figure 2 Histological and Immunohistochemistry features of pulmonary light chain deposition disease. (A) The deposits appear as an eosinophilic amorphous material surrounded by multinucleated giant cell reaction (arrows) on hematoxylin and eosin stain. (B) The deposits lack apple green birefringence with Congo red stain. Immunofluorescence with anti- $\kappa$ antibody (C, 100×, D, 200×) and anti- $\lambda$ antibody (E, 100× F, 200×) within the eosinophilic material.

patients with multiple cystic lesions in both lungs are more likely to experience rapid progression leading to pulmonary respiratory failure, which indicates an overall poorer prognosis $(16,17)$.

Due to the rarity of PLCDD diagnosis and the unusual morphology of these lesions, it is necessary to differentiate the different types of lung diseases with multiple cystic changes and multiple nodules. The main differential diagnoses of parenchymal cystic lesions are pulmonary Langerhans cell hyperplasia (PLCH), LAM, and lymphocytic interstitial pneumonia (LIP). PLCH generally affects males with a long history of smoking, 
mainly involves the upper and middle lung fields, and rarely involves the bilateral lung bases. Small nodules and cysts are the main manifestations in the early and late stages of the disease, respectively, and the prognosis may be regression, complete remission, or progression to honeycomb lung. Lam is a common disease in women of child-bearing age, which can manifest as pneumothorax and pleural effusion. LIP needs to be accurately identified, especially in patients with Sjogren's syndrome. Chest imaging has mainly shown LIP to cause multiple cystic lesions with central nodules and ground-glass opacity of bilateral lobules, and to be mainly distributed in the medial segment of the middle and lower lungs $(18,19)$. In addition, it is also necessary to distinguish PLCDD from pulmonary diseases with cystic wall vascular or angiographic characteristics of cystic lesions, and especially Birt-Hogg-Dubé syndrome. BHD syndrome is a genetic disease involving multiple systems. The observable features of BHD with chest imaging are cystic lesions of various sizes, mainly at the basal segment of lower lobe and the subpleural region. Of course, metastatic tumors, which usually have extrapulmonary manifestations, also need to be considered. Pulmonary nodules can be found early by chest CT reading, while cystic lesions are often ignored. Lung cancer can also be misdiagnosed, especially when solitary nodules are present (20). Besides the above imaging features, there are also reports that nodules with calcification are common in PLCDD. Three of the patients in this study had pulmonary nodules with calcification, and in cases such as these, the disease needs to be differentiated from tuberculosis.

PLCDD and primary amyloidosis share a similar pathogenesis as well as some clinical manifestations. In both diseases, deposits can be found in the walls of the bronchi or vessels, and eosinophilic amorphous material on hematoxylin and eosin stain and $\kappa$ light chain immunohistochemistry are diffusely positive within the amorphous material. However, unlike amyloidosis, which shows a reverse parallel $\beta$-fold secondary structure in deposits, PLCDD deposits are granular, do not form fibrils, and do not reveal applegreen birefringence under polarized light. Therefore, Congo red staining is needed to distinguish between the two diseases caused by $M$ protein deposition. In addition to the difference in their pathological manifestations, there are some differences in the imaging features of the diseases. Although nodules are common with amyloidosis, few cystic lesions are found in the lung, and research has indicated that there are different mechanisms in cystic formation. PLCDD is mainly deposited by light chains in lung tissue, which not only affects small airway but directly destroys alveolar structure (14). Meanwhile, amyloidosis may be caused by the infiltration of amyloid and inflammatory cells into the small airway, resulting in small airway stenosis, which indirectly leads to the corresponding alveolar expansion and damage (21).

PLCDD is caused by the deposition of monoclonal light chain proteins in the lung. When other organs are not involved, $M$ protein may not be detected in the blood or urine of patients. Arrossi et al. (15) reported and reviewed 39 cases of LCDD involving the lungs. The blood or urine of 21 of these cases were tested for M protein, but only 9 cases were positive and only 5 patients $(55.6 \%)$ were diagnosed as multiple myeloma. This suggests that the extrapulmonary organs of patients with $M$ protein detected in their blood or urine are more likely to be affected, and these patients have an increased likelihood of suffering from malignant hematological disease. In this study, only 2 of the 4 patients had weekly urine protein tests, all of which returned negative results. Therefore, tests to detect of $M$ protein in the blood or urine are needed to further exclude the extrapulmonary involvement of other organs and systems after surgery.

The removal of the abnormal plasma cell clone and the reduction of the synthesis and secretion of light chains are the ultimate goals of LCDD therapy. Due to the rarity of the disease and regular involvement of multiple organs, no unified treatment exists. At present, the treatment regimen is mostly based on the comorbidities (e.g., multiple myeloma, Sjogren's syndrome, and lymphoma) and complications, as well as the involvement of extrapulmonary organs. The clinical symptoms of the 4 cases in this study were mild. Three of the patients were ultimately diagnosed with Sjogren's syndrome. They were followed up regularly by the rheumatology department and treated with hormone and / or immunosuppressant therapy according to the severity of their condition. Inertia and slow progress have long been considered as features of such diseases (13). In our research, 2 of the 4 patients developed lesions during the follow-up period. A new left pulmonary nodule lesion was detected in 1 patient after 103 months of follow-up, while another developed an enlarged cystic lesion 2 years after follow-up. For patients with end-stage PLCDD, lung transplantation can be considered. Colombat et al. (10) reported 3 cases of severe cystic PLCDD that lead to lung transplantation. No recurrence of PLCDD was detected, but the long-term benefit of lung transplantation remains to be assessed. 
In conclusion, PLCDD is a rare disease that is poorly understood clinically and pathologically. PLCDD can be easily misdiagnosed or missed; especially on the basis of nodular lesions, it is easy to ignore the changes of bilateral pulmonary cysts. In this context, the diagnosis of PLCDD should be considered when there are multiple bilateral cystic lesions in the lung with pulmonary nodules, especially when blood vessels are present in the cystic wall or pass through the cystic lesions. Of course, the final diagnosis needs to be confirmed by open biopsy with frozen samples. Blood or urine tests to detect M-protein are strongly recommended once the pathological diagnosis is confirmed, to help eliminate the possibility of other tumors of the hematological system. At present, there are no accurate and ideal drugs for PLCDD, and the long-term benefit of lung transplantation remains to be assessed.

\section{Acknowledgments}

Funding: This work was supported by the National Science Foundation of China [NSFC. 81970039], Shanghai Municipal Commission of Health and Family Panning [201740019], [ZY(2018-2020) FWTX 3022].

\section{Footnote}

Data Sharing Statement: Available at http://dx.doi. org/10.21037/atm-20-2708

Conflicts of Interest: All authors have completed the ICMJE uniform disclosure form (available at http://dx.doi. org/10.21037/atm-20-2708). The authors have no conflicts of interest to declare.

Ethical Statement: The authors are accountable for all aspects of the work in ensuring that questions related to the accuracy or integrity of any part of the work are appropriately investigated and resolved. The study was approved by the Ethics Committee of Shanghai Pulmonary Hospital (No. K19-168). All aspects of the study were performed in accordance with the relevant guidelines and regulations.

Open Access Statement: This is an Open Access article distributed in accordance with the Creative Commons Attribution-NonCommercial-NoDerivs 4.0 International License (CC BY-NC-ND 4.0), which permits the noncommercial replication and distribution of the article with the strict proviso that no changes or edits are made and the original work is properly cited (including links to both the formal publication through the relevant DOI and the license). See: https://creativecommons.org/licenses/by-nc-nd/4.0/.

\section{References}

1. Randall RE, Williamson WC Jr, Mullinax F, et al. Manifestations of systemic light chain deposition. Am J Med 1976;60:293-9.

2. Nasr SH, Valeri AM, Sethi S, et al. Clinicopathologic correlations in multiple myeloma: a case series of 190 patients with kidney biopsies. Am J Kidney Dis 2012;59:786-94.

3. Nasr SH, Valeri AM, Cornell LD, et al. Renal monoclonal immunoglobulin deposition disease: a report of 64 patients from a single institution. Clin J Am Soc Nephrol 2012;7:231-9.

4. Pozzi C, Fogazzi GB, Banfi G, et al. Renal disease and patient survival in light chain deposition disease. Clin Nephrol 1995;43:281-7.

5. Lin J, Markowitz GS, Valeri AM, et al. Renal monoclonal immunoglobulin deposition disease: the disease spectrum. J Am Soc Nephrol 2001;12:1482-92.

6. Gandhi D, Wee R, Goyal M CT and MR imaging of intracerebral amyloidoma: case report and review of the literature. AJNR Am J Neuroradiol 2003;24:519-22.

7. Halatchev IG, Zheng J, Ou J. Wild-type transthyretin cardiac amyloidosis (ATTRwt-CA), previously known as senile cardiac amyloidosis: clinical presentation, diagnosis, management and emerging therapies. J Thorac Dis 2018;10:2034-45.

8. Popovic M, Tavcar R, Glavac D, et al. Light chain deposition disease restricted to the brain: The first case report. Hum Pathol 2007;38:179-84.

9. Morinaga S, Watanabe H, Gemma A, et al. Plasmacytoma of the Lung Associated with Nodular Deposits of Immunoglobulin. Am J Surg Pathol 1987;11:989-95.

10. Colombat M, Stern M, Groussard O, et al. Pulmonary cystic disorder related to light chain deposition disease. Am J Respir Crit Care Med 2006;173:777-80.

11. Kijner CH, Yousem SA Systemic light chain deposition disease presenting as multiple pulmonary nodules. A case report and review of the literature. Am J Surg Pathol 1988;12:405-13.

12. Sayed RH, Wechalekar AD, Gilbertson JA, et al. Natural history and outcome of light chain deposition disease. Blood 2015;126:2805-10. 
13. Sheard S, Nicholson AG, Edmunds L, et al. Pulmonary light-chain deposition disease: CT and pathology findings in nine patients. Clin Radiol 2015;70:515-22.

14. Colombat M, Caudroy S, Lagonotte E, et al. Pathomechanisms of cyst formation in pulmonary light chain deposition disease. Eur Respir J 2008;32:1399-403.

15. Arrossi AV, Merzianu M, Farver C, et al. Nodular pulmonary light chain deposition disease: an entity associated with Sjogren syndrome or marginal zone lymphoma. J Clin Pathol 2016;69:490-6.

16. Hirschi S, Colombat M, Kessler R, et al. Lung transplantation for advanced cystic lung disease due to nonamyloid kappa light chain deposits. Ann Am Thorac Soc 2014;11:1025-31.

17. Colombat M, Mal H, Copie-Bergman C, et al. Primary cystic lung light chain deposition disease: a clinicopathologic entity derived from unmutated B cells

Cite this article as: Wei P, Tao R, Liu Y, Xie H, Jiang S, Yu D, $\mathrm{Lu} \mathrm{H}$, Cao W. Pulmonary light chain deposition disease: a case series and literature review. Ann Transl Med 2020;8(9):588. doi: 10.21037/atm-20-2708 with a stereotyped IGHV4-34/IGKV1 receptor. Blood 2008;112:2004-12.

18. Johkoh T, Muller NL, Pickford HA, et al. Lymphocytic interstitial pneumonia: thin-section CT findings in 22 patients. Radiology 1999;212:567-72.

19. Egashira R, Kondo T, Hirai T, et al. CT findings of thoracic manifestations of primary Sjogren syndrome: radiologic-pathologic correlation. Radiographics 2013;33:1933-49.

20. Makis W, Derbekyan V, Novales-Diaz JA Pulmonary light and heavy chain deposition disease: a pitfall for lung cancer evaluation with F-18 FDG PET/CT. Clin Nucl Med 2010;35:640-3.

21. Seaman DM, Meyer CA, Gilman MD, et al. Diffuse cystic lung disease at high-resolution CT. AJR Am J Roentgenol 2011;196:1305-11. 